\title{
College English Teaching Innovation Strategy Research from the Perspective of Functional Translation Theory
}

\author{
Li Meijing \\ Foreign Language Department \\ Jilin Business and Technology College \\ Changchun, China \\ 182076127@qq.com
}

\begin{abstract}
At present, English education in colleges has been improved greatly in the development process of the times, but hasn't experienced a fundamental change. In essence, college English education still maintains the traditional college English teaching mode. The development of the society has put forward higher requirements for English talents. Obviously, the traditional college English teaching mode has hindered the development of college English education. Since China joined the world trade organization, the quality of the English translation is paid more and more attention to, which needs innovation in college English teaching mode under the guidance of functional translation theory. This paper discusses English teaching innovation strategy in college from the perspective of functional translation theory.
\end{abstract}

Keywords-functional translation theory; college English teaching; innovation strategy research

\section{INTRODUCTION}

With the constant improvement of social development level, education curriculum reform is also gradually deepening. The functional translation theory has the important influence on college English teaching reform and innovation. The traditional concept of translation equivalence no longer adapts to the development of modern society and current English talent demand, so, it is necessary to constantly innovate English teaching research and strengthen college students' English language application ability, which can keep college English teaching development stepping forward. As is known to all, English language learning is a process which needs language learners to constantly communicate with others in language context. Translation is inevitable in the process of language communication. Translation occupies the important position in college English teaching and is also an important part of the English language learning. English translation is a dynamic process of language output, which can test the results of English language learning. At the same time, it is of great significance to improve the language application ability of college students. Traditional English translator can no longer meet the demand of modern college English teaching ${ }^{[1]}$. Under this circumstance, functional translation theory gradually provides an important prerequisite for the English teaching in college. Only when college English teaching is constantly innovated and keeps new vitality can it adapt to the development level of modern society and enhance students' language application ability.

\section{FUnCTIONAL TRANSLATION THEORY}

\section{A. The Definition of Functional Translation}

Functional translation theory was put forward in the 1970s, which is a new theory taking Skopos theory as the core. From the perspective of functional translation, translation work is a form of communication with certain particularity, which mainly puts emphasis on the following two points, namely, the function of text and translation. Text includes source text, target text and schema text. A source text is a text from which information or ideas are derived. In translation, a source text is the original text that is to be translated into another language. Schema text is produced after the cognition of source text. Based on this, target text is transformed as a result. However, in actual translation practice, in addition to considering the rhetorical function of the source language, translators should also take the purpose of translation and the target language readers into account. Therefore, the process of translation is not a simple language transformation, but to establish communication between two kinds of language and culture. Functional translation theory is to build translation on the translation methods and skills and choose to use different translation methods according to the different translation purposes $^{[2]}$

\section{B. The Application of Functional Translation Theory}

From the perspective of value theory, functional translation theory is more realistic than traditional translation theories. It is focused on the target language translation context and views readers' language and culture understanding ability as the key of translation, which implies that English translation is not simple inter-lingual conversion but includes more cultural elements expressed in the form of language. So, there are many subjective colors in the process of English translation, implementing the creativity and innovation of language expression. To analyze the English translation from the perspective of functional translation theory is to introduce action theory into the field of translation. On the expression of 
language, the first thing to do is to fully express the intention of the source language and found a common ground between the information of the source language and target language through fusing their different kinds of language and culture, on the basis of this, it is probable to achieve cultural transformation between two languages and convey the content of the source language accurately to the target language readers. Therefore, in the process of translation, the readers' understanding ability must be taken as the standard of English translation.

\section{PRESENT Situation Of COLLEgE ENGLiSh Translation} TEACHING

\section{A. Lack of Reasonable Translation Curriculum and Teaching Material}

In the process of English translation, constant practice can deepen students' understanding of the English cultural background. At the same time, students also can carry on a contrast between the Chinese and foreign cultural differences, which is of great significance to language communication. The development of English translation can largely enhance and improve the students' English application ability and level. However, the English teachers in colleges haven't paid enough attention to scientific and reasonable translation courses and fail to design appropriate and applicable curriculum for college students. From the English teaching practice of a number of colleges, translation course still plays an unimportant role in the teaching work and fails to improve students' English capability $^{[3]}$.

Therefore, setting up relevant translation course can enable students to study in the complete system and enhance their professional knowledge and skills for translation, so as to keep practicing. Reasonable and professional English translation course is able to ensure that students can actively absorb professional teachers' translation theory, enhance their interest in English translation and thus improve their autonomous learning ability. Translation course setting needs teachers who have professional translation practice and rich experience in translation teaching to participate in, so that they can provide important guidance for students, strengthen students' understanding of the English translation ability and reduce the possibility of students' misunderstandings for English translation and thus set up the correct concept of translation for students.

From the preparation of textbooks, there is a serious lack of translation teaching materials for non-English majors. To compare with, the widespread used comprehensive teaching materials, such as New Horizon College English Textbook which is divided into "reading and writing tutorials", "listening and speaking tutorials", "audio-visual tutorials" and "comprehensive training tutorials", are not a specialized teaching material. Translation is regarded as a means of testing English proficiency, whose structure is relatively simple and coverage is relatively narrow. These are coincidently the current problems of college English translation. It can be clear from the exercise types of college English translation that translation in many cases is only limited to the English proficiency test approach. Therefore, the design of the curriculum structure is relatively simple. College English teachers are mostly English majored and has some skills in controlling English language. However, because of the strong applicability of translation, college English teachers haven't made a breakthrough in the theoretical teaching mode of translation. In the face of the society's demand for high-end translation talents, college English teachers feel powerless due to lacking of practical experience in translation.

\section{B. Lack of Professional Theory Guidance}

Students in learning English will inevitably encounter some theoretical problems difficult to solve, which requires professional teachers to provide theoretical guidance. But many college English teachers are directly engaged in the teaching work after graduation. Although they are provided with some professional theories, their actual experience of translation teaching is still insufficient. From the current teaching practice, many colleges don't pay enough attention to English translation theory teaching.

Correspondingly, there is also a great lack of professional translation theory teachers. Students and teachers are two main subjects in the teaching process, so the lack of the important participation of teachers will increase the difficulty of the students' learning in the process of English translation. Students lack of professional theoretical guidance feel it difficult to form a complete system of knowledge in the translation study, which also exerts a certain negative impact on the mastery of English knowledge. At the same time, many college students will encounter some problems about switching between English and mother language and fail to use appropriate methods and skills of English translation in the process of learning English. College English teaching lays little emphasis on functional translation theory, so it is difficult to play the advantages of functional translation theory in the process of teaching ${ }^{[4]}$. As a matter of course, students feel it difficult to improve their English level and learning ability through professional learning of theoretical knowledge.

\section{College ENGLish TEACHING INNOVATION BASED ON FUNCTIONAL TRANSLATION THEORY}

Language is a comprehensive subject, which requires students to cover a wide range of knowledge and improve the understanding of knowledge from all aspects. Translation as a carrier of different languages, whose purpose is to convey information accurately, so, in the process of translation, it is necessary to adopt proper translation methods in order to achieve the accurate comprehension of target readers. Translation is mainly used in communication cases to complete the conversion of different languages and achieve communication between different cultures, so the function of translation is to serve as a bridge between the two languages and cultures in order to facilitate cross-cultural communication. In college English teaching, it is necessary to proceed from the basis of translation functions, train students to use the functions of translation theory in English learning and improve their accurate positioning for language translation.

From the functional perspective, English translation should be coherent and objective according to the type of translation 
text. College English teachers should focus on the following

TABLE I. THREE STEPS TO IMPROVE COLLEGE ENGLISH TEACHING UNDER THE GUIDANCE OF FUNCTIONAL TRANSLATION THEORY[4]

\begin{tabular}{|l|l|}
\hline Step 1 & $\begin{array}{l}\text { Cultivate students' thinking habits of English learning using } \\
\text { functional translation theory }\end{array}$ \\
\hline Step 2 & $\begin{array}{l}\text { Enhance college students' accurate positioning for the purpose of } \\
\text { English translation }\end{array}$ \\
\hline Step 3 & $\begin{array}{l}\text { Enhance students' autonomous learning ability in English } \\
\text { translation }\end{array}$ \\
\hline
\end{tabular}

A. Cultivate Students’ Thinking Habits of English Learning Using Functional Translation Theory

Innovation is the driving force for the development of a nation, and it is also of great significance to the development of educational work. Under the guidance of the functional translation theory, the innovation of college English teaching and learning has been gradually strengthened, which can play an important role in enhancing the students' ability of English application. Translation is an important carrier of the exchange between different languages and provides an important prerequisite for communication between people. So, it is necessary to cultivate students' thinking habits in the use of functional translation theory and to enhance the ability of students to use functional translation theory to carry out English translation. English translation requires coherence of college, so college English teachers need implement the coherence to students' daily translation writing to guide the process of translation under the guidance of functional theory, so that the students can develop the habit of thinking in daily contact. At the same time, it should be noted that the English translation is a highly subjective work. When different people involve in translation, the translation is not the same. College students in the process of the English translation will inevitably add some subjective thoughts themselves, but what the teachers need to do is to let the students understand the advantage of creative subjectivity and reduce the problem caused by translators' subjectivity as much as possible. The use of functional translation theory in English learning can greatly enhance the students' understanding of the translation so that students can grasp the main direction of the translation.

\section{B. Enhance College Students' Accurate Positioning for the Purpose of English Translation}

To apply functional translation theory to practical English translation, it is necessary to understanding the source text comprehensively, especially for the purpose of translation. To accurately position the purpose of the translation material, translators need to judge whether it is academic or commercial. Teachers need to focus on informing the students about the importance of the purpose of translation in the process of English teaching, thus, students are able to clear the purpose of translation and can better enhance the fluency of translation, so as to improve the quality of translation. It is a significant improvement of the traditional translation teaching mode to transform the literal translation to liberal translation, which can enhance the level of translation. In order to determine the main purpose of translation, in the process of actual translation, it is necessary to adjust the important aspects and take some practical and effective translation strategies according to the translation purpose. To find the main purpose of translation three steps to improve the teaching effect. See TABLE 1.

materials, students need a lot of practice and gradually improve their knowledge and ability related to translation.

In the practice of college English teaching classroom, through the constant practice of translating some short essays, students' ability to obtain the purpose of translation can be enhanced. In addition, college English teachers can also increase the amount of students' English reading materials and gradually enrich students' experience in translation. According to the relevant context, we need to continue to explore key information so as to be able to better grasp the main purpose of translation. Functional translation theory can help students to set up the function consciousness and accumulate experience in translation practice so as to improve the level of English translation. In addition, in the process of translation teaching in college English, writing is also very important. Only students have mastered certain cultural knowledge and comprehensive language ability can they have a good command of the source language thought in the process of translating and transmit the culture of source language in the specific context.

So, English teachers should process the source language text in English translation teaching from the perspective of functional theory and employ various translation techniques, such as selective translation, interpretation and adaption translation, which all need students to master the ability of processing source language. In practical teaching, it is necessary to provide practice opportunities for students, strengthen students' ability of interpreting and translation and cultivate students' understanding of text mode for language translation.

\section{- C. Enhance Students' Autonomous Learning Ability in English Translation}

Students are the key participants in the learning process. With the guidance of functional translation theory and instruction of professional teachers, the participation of students is equally important. College students have already experienced English learning for a long stage and usually have their own specific methods in learning English. Therefore, in the process of English learning, there will be a great advantage as for college students. In order to gradually enhance and improve the ability of students to learn English translation independently, students need really become the dominant in the learning process. Learning English needs a long-term accumulation and practice, because learning in a short term will not have a good learning effect. If students want to be able to improve their ability to use the language successfully, they need to keep learning and practicing English every day. English translation is one of the most important methods to enhance students' English learning ability, so students need to translate English translation with the consciousness of the real practical value of functional translation theory in the process of daily practice. According to the need of translation materials, we must first be able to master each of the words contained in the sentence, then also need to carefully analyze the sentence components among them, and finally translate in combination with the relevant context according to the purpose of the main functional materials. 


\section{SUMMARY}

As English is widely used in the modern society, it is necessary to pay attention to the teaching of students' English teaching innovation and improve people's ability to use English. The functional translation theory is one of the important ways to improve the English application level of college students.

However, in the practice of English teaching in many colleges, there are some problems in the use of the functional theory, such as lack of proper translation in the teaching of college courses and students' lack of professional guidance of translation theory. The existence of these problems will definitely affect the students' learning and are disadvantageous to the smooth development of innovative teaching in colleges. It can receive good effect for the innovation of college English teaching to cultivate students' use of functional translation theory in developing habits of thinking in the English learning, enhance students' accurate positioning of English translation purpose and enhance students' autonomous learning ability in English translation.

\section{REFERENCES}

[1] Xie Yanhong. The application of functional translation theory in college English translation teaching[J]. Journal of Luoyang Normal University,2010,(04)

[2] Zhang Huanmin. College English innovation under the functional translation theory[J]. Journal of Hubei Correspondence University, 2015, (8):164-165

[3] Feng Huan. Study on the English translation of the college art teaching based on the interpretive theory [J].Art Education, 2015,(7):139

[4] Zhou Daofeng. The innovation strategy of college English teaching under the function of translation theory [J].Journal of Baoji University of Arts and Sciences (Social Science Edition),2013, (12):163-165 